\title{
EDUCAÇÃO PARA QUALIDADE DE VIDA: CONTRIBUIÇÕES DA EDUCAÇÃO ESTATÍSTICA
}

\author{
Diva Valério Novaes \\ Instituto Federal de Educação, Ciência e Tecnologia de São Paulo, Brasil \\ divavn@ig.com.br
}

Estudos de pesquisadores de diversas áreas, em articulação com aspectos da legislação educacional brasileira, convergem para uma visão educacional afinada com qualidade de vida. Novaes (2011), estudou concepções didáticas de professores apontando que os mesmos sentem necessidade de contribuir para um melhor desempenho de seus alunos em diversos âmbitos da vida, porém, não se sentem capacitados para essa atuação. Dado que pesquisadores em Educação Estatística apontam seu potencial para formar cidadãos em múltiplos aspectos da vida, propusemos a alunos de cursos de licenciatura, estudar a integração da Estatística com sua área, em busca desta atuação de maneira transdisciplinar. Com base na legislação nacional, princípios da análise exploratória de dados, escolha do contexto, descrição das variáveis didáticas e aprendizagem favorecida com elas, estes criaram atividades que permitiram trabalhar o conteúdo especifico, e simultaneamente os objetivos sociais da Educação Básica. Discutimos o desenvolvimento de uma dessas atividades e as possibilidades didáticas permitidas com esta experiência.

\section{INTRODUÇÃO}

Diversos pesquisadores afirmam que uma nova perspectiva para a vida humana nos move neste início de século, requerendo que troquemos nossas lentes para visualizer as mudanças necessárias à educação no século XXI. Tomamos consciência de que a evolução do progresso científico não está afinada com a evolução humana e nem com a manutenção da vida na Terra. $\mathrm{O}$ crescente mal-estar social e a fragilidade nas relações interpessoais, contrastando com o gigantismo das inovações tecnológicas é bastante discutido por muitos autores, por exemplo:

\begin{abstract}
O homem tem se preocupado mais em fazer do que em ser. O grande dilema do século XXI está na formação do interior do homem, para que vivenciado valores possa influenciar a sociedade. O grande desafio do homem, conquistador crescente de todas as técnicas, está em crescer interiormente, na mesma medida, procurando tirar da reflexão e de uma visão transcendental, os elementos capazes de dominar a ciência e de colocá-la à disposição da humanidade, sobre ajudá-la a crescer nos mesmos padrões necessários para gerar felicidade. (MARTINS, 2010, p.39).
\end{abstract}

$\mathrm{Na}$ área profissional, Wong (2009) afirma que nos dias de hoje, pessoas são admitidas por seus conhecimentos técnicos e demitidas pelo comportamento pessoal. Mussack (2003), também discute esse problema e afirma que alguns dos motivos para essas demissões são: dificuldade de convivência, de comunicação, de organização, de aceitar liderança, de administrar conflitos, impontualidade, desinteresse, recusa ao comprometimento, despreocupação com a inovação, e principalmente, capacidade de ir além do convencional. Segundo este autor, uma das justificativas para esse fato, é que a formação pessoal, frequentemente é esquecida na formação acadêmica.

Por outro lado, a Lei Federal n.9.394/96, LDB- Lei de Diretrizes e Bases da Educação Nacional e a Resolução n04/2010 que define Diretrizes Gerais para a Educação Básica apontam como finalidade para essa modalidade de educação, preparar para a vida, para o mundo do trabalho, para estudos posteriores e para o aprendizado permanente. Notamos no Art. $6^{\circ}$ da resolução n.04/2010 o que segue:

$\mathrm{Na}$ Educação Básica, é necessário considerar as dimensões do educar e do cuidar, em sua inseparabilidade, buscando recuperar, para a função social desse nível da educação, a sua centralidade, que é o educando, pessoa em formação na sua essência humana. (RESOLUÇÃO n.04/2010)

A lei federal n. 12.288/2010 institui o estatuto da desigualdade racial. Orienta ações para coibir toda forma de discriminação baseadas em raça, cor, gênero, descendência, origem nacional

In: M.A. Sorto (Ed.), Advances in statistics education: developments, experiences and assessments. Proceedings of the Satellite conference of the International Association for Statistical Education (IASE), July 2015, Rio de Janeiro, Brazil. (C)2015 ISI/IASE iase-web.org/Conference_Proceedings.php 
ou ética que restrinja o reconhecimento de direitos humanos e liberdades fundamentais em qualquer campo da vida pública ou privada. A seção II, do capítulo II da referida lei é todo direcionado à missão da educação nesse processo. Consta nesta lei, que o poder público incentivará instituições de ensino superior, públicas e privadas a incorporar nas matrizes curriculares dos cursos de formação de professores, temas que incluam valores concernentes à pluralidade étnica $\mathrm{e}$ cultural da sociedade brasileira.

Com base no que consta na constituição Federal, a lei $n^{\circ}$ 9.795/1999 institui a Política Nacional de Educação Ambiental, e especifica princípios e objetivos para a educação ambiental:

Art. $\mathbf{2}^{\circ}$ A educação ambiental é um componente essencial e permanente da educação nacional, devendo estar presente, de forma articulada, em todos os níveis e modalidades do processo educativo, em caráter formal e não-formal.

Art. $3^{\mathbf{0}}$. II - Cabe às instituições educativas, promover a educação ambiental de maneira integrada aos programas educacionais que desenvolvem.

Neste contexto, os educadores estatísticos são unânimes em afirmar que o pensamento estatístico favorece a criação de habilidades que capacitam o sujeito a analisar situações considerando todos os aspectos envolvidos nas mesmas, favorecendo a atuação tanto na vida pessoal quanto profissional. $\mathrm{O}$ hábito de analisar diversos aspectos de uma situação, segundo Rumsey (2002), Garfield (2002) e o documento GAISE (Franklin ET AL., 2007), pode facilitar escolhas com base em dados que favoreçam melhor atuação dos indivíduos em sociedade. Segundo Gal (2002), é possível adquirir uma postura crítica, que pressupõe atitude de questionamento diante de mensagens que podem ser enganosas, desproporcionais, parciais ou incompletas.

Entendemos que as discussões anteriores descrevem nossa realidade social e educacional e convergem para uma visão educacional que comporta todos esses aspectos simultaneamente: educar para a qualidade de vida, em suas múltiplas dimensões.

Esses aspectos educacionais constituem preocupação de professores que atuam na Educação Básica. Novaes (2011), estudou concepções didáticas e específicas dos professores da Educação Básica sobre a variabilidade estatística. Entre as dezesseis concepções identificadas neste estudo, cinco foram caracterizadas como 'professor educador'. Ou seja, o professor não quer apenas trabalhar o conteúdo específico de sua disciplina. Manifesta desejo de contribuir para o progresso de seu aluno em outros âmbitos da vida. Porém, este estudo identificou também, que o professor não sabe como fazer isso de maneira programada. Atua quando surge oportunidade de discussão frente a eventos que ocorrem na sala de aula. Não existe um currículo preparado para esta finalidade.

Com o objetivo de dar sequência ao estudo de Novaes (2011), em busca de prática para o resultado da pesquisa, desafiamos os alunos de Cursos de Licenciatura em Matemática, Física e Geografia a criar atividades que permitissem o estudo do conteúdo específico proposto no plano de ensino da disciplina, com auxílio da Estatística aplicada em sua área de atuação, e, simultaneamente, contemplar nestas atividades os objetivos sociais da Educação Básica. Ou seja, elaborar atividades que discutam de maneira transdisciplinar, um ou mais aspectos da formação que considera as observações dos pesquisadores e a legislação discutidos anteriormente.

Descrevemos a seguir o planejamento das atividades com 58 alunos, destes três Cursos de Licenciatura de uma instituição pública federal. Na sequência discutimos o desenvolvimento de uma das atividades, por um grupo de alunos do Curso de licenciatura em Geografia.

\section{PLANEJAMENTO DA ATIVIDADE}

Após discussão sobre o cenário social e educacional descrito anteriormente, seguiu-se a leitura e discussão do texto de Shulman (2005), que salienta os setes conhecimentos necessários à atuação do professor. Discutimos ainda, a distinção entre professor tradicional e construtivista, Leão (1999), aspectos da Educação Crítica, Skovsmose (2007). Em rápida visão da modelização da Teoria das Situações Didáticas de Brousseau (1986), discutimos seus princípios e as fases de ação, formatação, validação e institucionalização. 
No contexto que estamos trabalhando, ao elaborar uma atividade para os alunos temos sempre em mente: o conteúdo específico proposto no plano de ensino, uma metodologia para o processo de ensino e aprendizagem, o contexto onde se desenvolverá a atividade, as variáveis didáticas que serão consideradas neste contexto e os aspectos educacionais que serão favorecidos com as variáveis didáticas estabelecidas. Assim, a elaboração da atividade foi precedida de uma discussão embasada no seguinte roteiro:

I. Conteúdo do programa de ensino a ser abordado.

II. O desenvolvimento da atividade se dará com o objetivo de favorecer um ou mais aspectos da preparação para a cidadania, para o mundo do trabalho, para estudos posteriores e o aprendizado permanente, como consta na LDB.

III. O tema que norteará a elaboração das atividades e a escolha dos contextos, será a Educação para a qualidade de vida em suas múltiplas dimensões: Saúde física, Saúde emocional, Saúde Financeira, Bem estar social, Saúde ambiental, Saúde planetária, e outros.

IV. De acordo com o tema e o contexto escolhido fazer a descrição das variáveis didáticas associadas, buscando esgotar a possibilidade de variáveis didáticas que podem ser tratadas naquele contexto.

V. O desenvolvimento da situação segue os princípios da Teoria das Situações Didáticas de Brousseau (1986), visando colocar os alunos nas fases de ação, formatação, validação e institucionalização.

VI. Toda análise estatística envolvida na situação proposta ocorre segundo os princípios da Análise Exploratória de dados, segundo Batanero (2001).

\section{DESCRIÇÃO DE UMA DAS ATIVIDADES ELABORADAS}

Passamos a descrever uma das atividades desenvolvidas por um dos grupos de alunos (G4), do sexto semestre do Curso de Licenciatura em Geografia, intitulada Educação Socioambiental, proposta para alunos de uma escola pública estadual.

Propusemos aos licenciandos formar grupos em que pelo menos um integrante estivesse lecionando ou estagiando, para que as atividades pudessem ser elaboradas considerando o conhecimento de seus próprios alunos, suas características e contextos educativos, conforme Shulman (2005).

\subsection{Atividade proposta pelo G4:}

Solicitar aos alunos que separassem, durante uma semana rótulos das embalagens de produtos utilizados em suas residências e trouxessem para a escola no dia solicitado pelo professor. Dispostos em grupos, elaborar tabelas para registrar o produto e as diferentes marcas destes produtos utilizadas pelos mesmos. Resumir essas informações em gráficos apontando a frequência percentual de cada marca de um mesmo produto utilizado. Registrar em cartolina, os gráficos e tabelas elaborados por cada grupo e afixar na parede da sala de aula. O líder de cada grupo explicará suas representações e os alunos discutirão se as mesmas estão corretamente elaboradas. Por exemplo, se as tabelas estão representadas conforme ABNT, se o tipo de gráfico escolhido é adequado para o tipo de variável em estudo, se falta informações tais como, título do gráfico, o que está representado nos eixos, entre outras. Unificar as tabelas e gráficos, para obter os dados dos produtos utilizados por todos os alunos. Análise das informações contidas nas tabelas e gráficos.

A análise versa sobre as seguintes questões: Entre os produtos analisados, quais poderiam ser reciclados e quais de fato são reciclados; pelo tamanho do rótulo, estimar o tamanho da embalagem e o espaço ocupado por ela em descarte inadequado; quais produtos são nacionais e quais são estrangeiros e observar a diversidade e frequência de marcas de um mesmo produto utilizado nas residências dos alunos desta turma.

\subsection{Organização da atividade proposta pelo $G 4$}

Tema: Qualidade de vida ambiental e bem estar social.

Conteúdo específico: Preservação do ambiente e globalização - $3^{\circ}$ ano do Ensino Médio.

Contexto: cotidiano - rótulo de produtos domésticos utilizados na residência dos alunos.

Variáveis didáticas que poderão ser consideradas nesta atividade e contribuições esperadas: 
(1) Estudo do conteúdo específico proposto para a $3^{\circ}$ ano do Ensino Médio: A questão ambiental, preservação do ambiente e globalização. Contribui para o preparo para a vida/cidadania, conforme as finalidades da Educação Básica que constam no Art.22 da LDB.

(2) Trabalhar com os alunos dispostos em grupo, com um líder por grupo.

Favorece a discussão e o aprendizado para trabalhar em equipe. Esse aprendizado é valorizado na vida profissional. Contribui com o preparo para o mundo do trabalho (LDB).

(3) Trabalhar noções de variáveis estatisticas, porcentagens, representação de distribuições por meio de gráficos e tabelas, bem como, a leitura e interpretação das informações contidas nas representações.

Este estudo favorecerá análises e leituras de dados necessários ao desenvolvimento dos conteúdos específicos da geografia, atuais e posteriores. Permite a preparação para estudos posteriores e capacidade de analisar informações encontradas em diversos contextos da vida $(L D B)$.

(4) Possibilidade para os alunos agirem de maneira autônoma.

Os alunos têm autonomia para fazer representações gráficas, tabulares e escolha de medidas para fazer a análise solicitada, o que permite exercitar a criatividade e o aprender a aprender. Permite a preparação para o aprendizado permanente (LDB).

(5) Discussão sobre a globalização, relações com o consumo e desigualdade social.

Além dos aspectos constantes no plano de ensino e no livro didático desta turma é possível ampliar essa discussão. Segundo O'Sullivan (2004), o termo globalização pode ser examinado em dois contextos: "nova ordem econômica" e "organicidade planetária".

A integração global é uma mistura de bênçãos e maldições. Para algumas regiões no mundo todo, a globalização trouxe prosperidade e para outras, pobreza. Temos que olhar para o termo "globalização" criticamente e ver para onde as ideias globais estão nos levando, afirma este autor.

A primeira ideia de global surgiu há mais de vinte e cinco anos, quando vimos as imagens da Terra enviadas do espaço sideral, afirma O'Sullivan (2004). Essas fotografias nos fizeram ver que a Terra é uma entidade total e criou uma metáfora unificadora que despertou em muitos a consciência planetária. Surgiu a impressão de que todos os membros deste lindo planeta azul estavam inter-relacionados e no interior de uma intricada teia de vida. Essa é uma globalização diferente e contrária à globalização alimentada pelas potências industriais, comerciais e financeiras do mundo contemporâneo, que está entrando em sua fase predatória final. As demandas feitas ao planeta estão muito além daquilo que ele é capaz de proporcionar. Esse autor propõe outra globalização, que reconheça as biorregiões locais e também o valor inerente de cada componente da comunidade terrestre. $\mathrm{O}$ humano realiza-se no terrestre. $\mathrm{O}$ terrestre expressa-se no humano, pois, se os seres humanos progredirem às expensas da comunidade significa arruinar a ambos, O'Sullivan (2004).

Note que essa discussão sobre a globalização guarda uma relação com o consumo e com o reconhecimento de um estado de suficiência que garante a qualidade de vida. Os centros comerciais estão em busca de consumidores e não de cidadãos. Pode-se discutir com os alunos, como nossa sociedade satisfaz necessidades humanas fundamentais e interferências destas escolhas na qualidade de vida. Contribui com a formação para cidadania/vida, como consta na (LDB).

\subsection{Análise da Aplicação da atividade elaborada pelo G4}

Participaram da atividade 25 alunos e trouxeram rótulos de 15 produtos diferentes, com uma diversidade de quatro a nove marcas de cada um dos produtos. Na primeira fase da atividade em sala de aula, o professor solicitou aos alunos, dispostos em grupos, a representação dos dados obtidos em gráficos e tabelas e análise das informações contidas nos mesmos, da maneira que considerassem adequada. Na segunda fase, o líder de cada grupo comunicou aos demais a representação e análise por eles efetuada. Estabeleceu-se uma rica discussão e por fim o professor discutiu as falhas observadas e o que passou desapercebido por eles na análise.

Quatro dos cinco grupos que se formaram, não foram capazes de representar os dados em tabelas, apresentaram os dados listados em forma de rol. Precisaram de ajuda, para esboçar tabela e gráfico adequadamente. $\mathrm{O}$ quinto grupo esboçou adequadamente a tabela contendo nome do produto e sua respectiva frequência, porém, equivocadamente, calculou média utilizando os dados 
da frequência da variável. Note que a variável envolvida neste estudo era 'Marca do produto utilizado', portanto, variável qualitativa nominal, para a qual não faz sentido o cálculo de média.

O equívoco observado nesse grupo de alunos, nos leva a questionar se o conceito de variável estatística, de distribuição de frequência e de medidas estatística foi trabalhado com os mesmos, ou se apenas o algoritmo das medidas foi trabalhado. Denota ainda, a importância destes conceitos para que os alunos possam fazer análise exploratória dos dados em estudo.

No fechamento da atividade, o professor discutiu com os alunos o fato de que as embalagens de maionese, margarina, hambúrguer, refrigerante, creme dental, leite, antitranspirante, detergente, shampoo e iogurte, representando $66,67 \%$ dos rótulos apresentados podiam ser reciclados, porém, os alunos relataram que apenas as embalagens de refrigerante e leite eram recicladas por eles. Ou seja, para este grupo, apenas $13,33 \%$ do material que poderia ser reciclado, de fato o era. Esse fato, abriu a discussão de quanto material é acumulado, o espaço ocupado pelos mesmos em descarte inadequado, destino do material que pode ser reciclado.

Os produtos que são de marcas estrangeiras abriram a discussão sobre a globalização, como proposto no item (5), com boa participação e interesse dos alunos. Observaram que $75 \%$ deles consumiam os mesmos produtos e as mesmas marcas. Porém $25 \%$ consumiam outras marcas com preços diferenciados. Abriu a discussão sobre consumo, consumismo, diversidade e suas relações com a saúde financeira.

Além do que constava no livro didático dos alunos, sobre a globalização, a discussão ampliou-se com a leitura do texto de O'Sullivan (2004, pp.176-193) sobre globalização, competição e consumismo.

\section{CONSIDERAÇÕES FINAIS}

A atividade aqui discutida, e outras que não tivemos a oportunidade de discutir, despertaram nos futuros professores, uma forma de atuação que aponta a possibilidade de condução do processo de ensino e aprendizagem, considerando os aspectos ressaltados na introdução deste texto.

Nesta atividade destacou-se, no âmbito do processo de ensino e aprendizagem da Estatística, a importância de discutir o significado de variáveis estatísticas, distribuição de frequências e não apenas o algoritmo das medidas estatísticas. A ampliação da discussão sobre globalização, consumo, consumismo e suas relações com a saúde financeira e emocional de cada cidadão e organicidade planetária, também se destacou. É nossa tarefa educacional começar a entender a globalização que se apresenta como um ideal que nos leva ao século XXI, afirma O’Sullivan (2004). O mundo dos negócios transnacionais se preocupa com a troca, o comércio e a competitividade de qualquer tipo de mercadoria que a mente humana possa conceber ou fabricar. Cada propaganda na TV ou rádio passa a ideia de que seu produto é o único que não podemos deixar de comprar. Existe um processo sinistro, que se esconde por trás da camuflagem e confunde o cidadão comum, afirma este autor.

Antes do início da elaboração destas atividades questionamos os futuros professores sobre o que eles têm em mente quando preparam uma aula ou uma atividade para seus alunos. As respostas obtidas versaram sobre conhecimento do conteúdo, ou conhecimento do conteúdo e conhecimento didático do conteúdo. Porém, nenhum deles citou a preocupação com a função social da educação, como consta na legislação brasileira e como defendem os gestores de diversas áreas, que recebem no mundo do trabalho os profissionais que passaram por nossas escolas. No entanto, essa preocupação apareceu no estudo de Novaes (2011), em professores que contam com alguns anos de atuação e vivência na realidade educacional e social. Este estudo apontou que nesta fase, embora consciente da importância dessa atuação, falta-lhe formação para atuar de maneira articulada e programada. Esse fato aponta a importância desse trabalho no curso de formação de professores.

A despeito das leituras, do roteiro para o trabalho contendo exemplo de atividades realizadas por alunos do semestre anterior, das discussões que precederam a elaboração das atividades e das manifestações de interesse dos alunos para esse desafio, os esboços iniciais elaborados por $70 \%$ a $80 \%$ dos grupos que vimos trabalhando nos três anos de desenvolvimento destas atividades, constituíram em aulas expositivas tradicionais, sem a discussão didática proposta. Após serem instigados pela professora orientadora dos projetos, sobre os aspectos 
ausentes na proposta apresentada, os trabalhos ficaram prontos para aplicação somente após a terceira ou quarta versão apresentada pelos participantes. Concluímos que se esses professores não recebessem acompanhamento, não teriam avançado com base apenas em discussões teóricas. Constatou-se a importância de acompanhar sua prática, como meio de diagnosticar, clarificar e explicitar suas concepções implícitas que dificultam o processo de ensino e aprendizagem, em sua atuação como professores.

Constatamos ainda que a Educação Estatística, transdisciplinarmente introduzida em qualquer disciplina da Educação Básica, favorece o processo de ensino e aprendizagem em duas vertentes: introdução do conteúdo a ser abordado com temas próximos da vivência dos alunos e análise exploratória de dados, Batanero (2001). Pode-se instigar os estudantes na identificação do maior número de aspectos envolvidos em qualquer situação. A atuação com esses recursos didáticos, contribui para uma constante atitude de questionamento diante de mensagens que podem ser enganosas, desproporcionais, parciais e incompletas. Segundo Gal (2002), pessoas estatisticamente letradas, são capazes de utilizar informações adequadamente, pensar criticamente sobre elas e tomar boas decisões com base nelas. Esse nos parece um ingrediente fundamental a ser incluído na transformação da matriz educativa e pedagógica para este milênio, como propõem diversos educadores e profissionais, alguns dos quais citamos anteriormente.

\section{REFERÊNCIAS}

Batanero, C. (2001). Didáctica de la estadistica. Granada: Universidad de Granada.

Brousseau, G. (1986). Fondements et Méthodes de La Didactique des Mathématiques. Recherches em Didactique des Mathématiques, Grenoble, 7(2), 33-115.

Franklin, C., Kader, G. \& Mewborn, D. \& Moreno, J., Peck, R. \& Perry, M., et al. (2005). Guidelines for assessment and instruction in statistics education (GAISE) report: a pre-K-12 curriculum framework. Alexandria (VA, USA): ASA.

Gal, I. (2002). Conocimientos básicos de estadística en adultos: significados, componentes, responsabilidades. Revista Internacional de Estatística (Haifa, Israel), 70(1), 1-25.

Leão, D. M.M. (1999). Paradigmas Contemporâneos de Educação: Escola Tradicional e Escola Construtivista. Cadernos de Pesquisa, nº107, p.187-206. Julho/1999.

BRASIL (1996). Lei n. ${ }^{\circ}$ 9.394: Lei de Diretrizes e Bases da Educação. Diário Oficial da União, 23 de dezembro de 1996.

BRASIL (1999). Lei n. ${ }^{\circ}$ 9.795: Institui a Política Nacional de Educação Ambiental.

BRASIL (2010). Lei n. ${ }^{\circ}$ 12.288: Institui o Estatuto da Desigualdade Social.

BRASIL (2010). Resolução n. ${ }^{\circ}$ 4: Diretrizes Curriculares Nacionais Gerais para a Educação Básica. Conselho Nacional de Educação. Câmara de Educação Básica.

Martins, I. G. S. (2010). Introdução. In C.A.M. Souza, \& T.N. Cavalcanti (Coords.). Princípios humanistas constitucionais: reflexões sobre o humanismo do século XXI. São Paulo: Letras Jurídicas.

Mussak, E. (2003). Metacompetência: Uma Nova Visão do Trabalho e da Realização Pessoal. Editora Gente.

Novaes, D.V. (2011). Concepções de Professors da Educação Básica Sobre Variabilidade Estatística. Tese de Doutorado em Educação Matemática, PUCSP. Disponível em HTTP://www.pucsp.br/pos/edumat/

O’Sullivan, E. (2004). Aprendizagem Transformadora: Uma visão educacional para o século XXI. Tradução de Dinah A. Azevedo. Biblioteca Freiriana, v.8. São Paulo: Cortez: Instituto Paulo Freire.

Shulman, L.S. (2005) Conocimiento Y Enseñanza: Fundamentos de La Nueva Reforma 1.IN: Revista de Currículum y formación Del Profesorado, 9.2.1. Disponível em HTTP://www.ugr.es/local/Recfpro/92ART1.pdf2 acesso em 04/03/2015.

Skovsmose, O. (2007). Educação Crítica: Incerteza, Matemática, Responsabilidade. Tradução de Maria Aparecida V. Bicudo. São Paulo: Cortez Editora.

Wong, R. (2009). Menos razão e mais inspiração. Revista CIO, 23, 16-19.

Ramsey, D. J. (2002). Statistical literacy as a goal introductory statistics courses. Journal of Statistics education. V.10, n.03. Disponível em www.amstat.org/publications/jse/v10n3/rumsey2.html acesso em 14/03/2015. 